\title{
Donación y deliberación El lugar de la caridad en la ética empresarial
}

\author{
Agustín DOMingo MORATALla \\ Universidad de Valencia (España) \\ agustin.domingo@uv.es
}

\begin{abstract}
Resumen
$\mathrm{El}$ artículo analiza algunas aportaciones de la encíclica Caritas in veritate $(\mathrm{CiV})$ a la ética social contemporánea. Una aportación de gran valor hermenéutico porque integra tres categorías centrales en la ética contemporánea: globalización, deliberación y donación. Dedica especial atención al concepto de caridad en la primera y tercera parte del trabajo, primero analizando la presencia de este concepto en la ética social reciente en términos de des-privatización, después muestra la emergencia de la caridad en la ética empresarial. Entre las aportaciones que realiza la encíclica a la ética empresarial nos hemos detenido en las que afectan a las formas de gestión organizativa y que hemos llamado «nuevo management».
\end{abstract}

Palabras claves: globalización, deliberación pública, donación, ética social, ética empresarial, management estratégico, responsabilidad social.

\section{Donation and deliberation The place of charity in business ethics}

\begin{abstract}
The article discusses some results of the Caritas in veritate (CiV) to Social ethics. A hermeneutic revolutionary contribution because it integrates three basics categories in contemporary ethics: globalization, deliberation and donation. With special attention to the concept of charity in the first and third of the work, first analyzing the presence of this concept in recent social ethics in terms of de-privatization, then reveals the emergence of charity in business ethics. Among the contributions that the encyclical makes Business ethics we works in categories what affecting organizational and management methods we have called «new management».
\end{abstract}

Key words: globalization, public deliberation, donation, social ethics, business ethics, strategic management, social responsibility.

Doctor en Filosofía. Profesor Titular de Filosofía Moral y Política en la Universidad de Valencia (España). Amplió estudios en la Universidad Católica de Lovaina como Fellow en la Cátedra Hoover y fue Secretario General y Vicepresidente de la Comisión Justicia y Paz. Entre sus abundantes publicaciones cabe destacar Un bumanismo del siglo XX. El personalismo (1985), El arte de poder no tener razón. La hermenéutica dialógica de Gadamer (1991), Responsabilidad bajo palabra (1995), Ética y voluntariado (1998), Calidad educativa y Justicia social (2002), Ética de la vida familiar. Claves para una ciudadanía comunitaria (2006). 


\section{Introducción}

La nueva encíclica de Benedicto XVI lleva un título filosóficamente revolucionario: Caritas in veritate (CiV). «Caridad» y «verdad» son dos términos que suelen aparecer por separado en las investigaciones filosóficas. Mientras el primero se sitúa dentro del ámbito de la filosofía práctica; el segundo, en cambio, dentro del ámbito de la filosofía teórica. Una separación alimentada desde tradiciones filosóficas que interpretan el uso público y el uso privado de la razón como si la vida humana estuviera organizada por dos lógicas diferentes. Una separación que dejaría la caridad en manos de la psicología de las emociones y la verdad en manos de la epistemología del conocimiento científico. Una separación que condenaría la caridad a la arbitrariedad de las emociones y la verdad a la universalidad de las razones. De esta forma, mientras que los actos de generosidad, altruismo, caridad o donación caerían fuera de la racionalidad filosófica; los argumentos lógicos, normativos y científicos serían propiamente filosóficos.

Podríamos conformarnos con esta separación y plantear que el texto de Benedicto XVI es radicalmente teológico y que, por consiguiente, carece de relevancia para la filosofía en cualquiera de sus dimensiones. Incluso se podría llegar a decir que no es una encíclica típicamente moral como otras sino «una encíclica social atípica, más teológica que moral (...) lo que hay de reflexión moral en ella parte de un enfoque explícitamente teológico, de modo que CiV habla del comportamiento humano y de las estructuras sociales desde la comprensión de Dios». «Estamos ante la primera encíclica social que tiene un enfoque explícitamente teológico, y no exclusivamente moral: en todo caso, un enfoque moral pero desde la perspectiva teológica» ${ }^{1}$.

Si aceptásemos esta separación no sólo seríamos injustos con nuestra propia experiencia de creyentes comprometidos por un mundo más justo motivados por nuestra comprensión de Dios, sino con las tradiciones filosóficas radicales que han entendido al ser humano de una manera integral. En la fenomenología hermenéutica y el personalismo comunitario los términos de «donación»y «deliberación» están estrechamente relacionados, como lo están los de «caridad» y «verdad». No están separados porque hay una antropología radical y relacional que los vincula, una antropología de matriz fenomenológica que los mantiene en una tensión productiva. Esta tensión entre caridad y verdad, entre donación y deliberación, no sólo se ha hecho presente en el ámbito de la 1 I. CAMACHO: "Primera encíclica social de Benedicto XVI: claves para su
comprensión", Revista de Fomento Social, 256 (2009), 629-654, 632; 650. 
filosofía analítica contemporánea cuando Quine, Davidson o Rorty hablan de «principio de caridad», sino que desempeña un papel central en las éticas hermenéuticas de Gadamer, Ricoeur y Greisch ${ }^{2}$. Incluso es fundamental para entender el papel de la Teología en la era del pragmatismo ${ }^{3}$.

La encíclica no puede leerse fuera de este contexto filosófico que le da sentido como si fuera un texto cuyo valor fuera únicamente teológico. El enfoque explícitamente teológico no invalida sus posibilidades para afrontar los grandes desafíos de la humanidad, y hacerlo de una manera fecunda para creyentes y no creyentes, para investigadores serios que con independencia de su fe confían en la razón humana con voluntad de verdad, incluso para científicos responsables indignados por lo injusto. Incluso deberíamos preguntarnos si esta matriz teológica es relevante para campos de la ética aplicada como la ética empresarial. ¿Qué novedad aporta esta encíclica a la ética empresarial? ¿Es legítimo que nos preguntemos por el lugar de la caridad en la ética empresarial? ¿Puede un empresario excluir la caridad de su horizonte profesional y decirle con sinceridad a un teólogo "२qapatero, a tus zapatos»?

Responderé a estas preguntas en tres tiempos. Primero analizaré lo que voy a llamar «des-privatización» de la caridad en la ética social, segundo presentaré los cambios en la ética social a los que invita la encíclica y en un tercer momento me preguntaré por el lugar de la caridad en la gestión empresarial.

\section{La desprivatización de la caridad en la ética social}

\section{Un punto de partida revolucionario}

La encíclica participa de una convicción importante de algunas éticas contemporáneas que no buscan la corrección política: la continuidad entre las diferentes esferas de la vida humana, es decir, la unidad de la vida humana en sus dimensiones íntima, privada y pública. Este planteamiento propio de las tradiciones fenomenológicas y del personalismo comunitario (explícitamente citado en el $n^{\circ} 42$ para hacer frente a lecturas fatalistas de la globalización), considera que los actos de generosidad, caridad y altruismo participan de una lógica o racionalidad

\footnotetext{
2 Cfr. J. Greisch: Le buisson ardent et les lumières de la raison. Vol I, II, III, Du Cerf, Paris 2004.

3 Cfr. L. Oviedo: "La Teología en la era del pragmatismo. El desafío pragmático", Antonianum 72 (1997), 217-250.
} 
que integra el conjunto de actividades humanas. A diferencia de tradiciones que separan ética privada y ética pública, virtudes privadas y virtudes públicas, el texto de Benedicto XVI muestra la continuidad de ámbitos y la unidad de la vida humana.

Esta unidad y continuidad en el conjunto de los actos de la vida humana es la que permite plantear, en el nivel de la reflexión teórica, la conexión entre saberes: Teología, Antropología, Economía o Política. Y también la que permite romper algunos presupuestos de las ciencias sociales cuando separan entre los niveles micro y los niveles macro, dejando la caridad para las relaciones micro-sociales y la justicia para las relaciones macro-sociales. Este presupuesto metodológico ha sido desterrado por la realidad moral de la vida personal o comunitaria donde la caridad tiene efectos sociales, políticos, económicos y culturales. En el panorama de las investigaciones sociales actuales es un punto de partida que algunos han calificado como revolucionario porque «no hay escuela de pensamiento relevante que afirme a la caridad como sustancia o principio de las relaciones macrosociales» ${ }^{4}$.

Esto no significa que la caridad no sea una preocupación en el conjunto de las ciencias sociales porque cada vez es mayor el número y la calidad de los trabajos que valoran su impacto en la ética social ${ }^{5}$. Las investigaciones sobre el voluntariado, el protagonismo del «tercer sector» en los procesos de cambio social, la economía de comunión y la consolidación de una ciudadanía activa que no excluye las prácticas comunitarias de solidaridad, son buena muestra de la des-privatización de la caridad. Incluso podemos afirmar que hay toda una tradición ética filosóficamente relevante que no ha necesitado participar de este proceso de des-privatización de la caridad porque en la articulación de la ética social ha planteado siempre una continuidad entre las diferentes esferas de la vida. Una tradición que ha reconstruido las modernidades sin segregar la caridad a la vida privada y la justicia a la vida pública, sin

4 Cfr. R. GonzÁlez FABre: “CiV: una clave de lectura”, Razón y Fe, 1334 (2009), 351. Una reconstrucción interesante del impacto social de la caridad y el altruismo en las ciencias sociales y la teología contemporánea puede encontrarse en L. OvIEDO: Altruismo y Caridad. Ensayo de antropología en clave disciplinar. Pontificio Athenaeum Antonianum, Roma 1998. Una buena adaptación de los planteamientos de Paul Ricoeur y sus aportaciones a la ética social pueden encontrarse en J. D. CAUSSE: El don del agapé, Sal Terrae, Santander 2006.

5 En el ámbito de las ciencias sociales de tradición anglosajona se ha reconocido explícitamente la deuda con las tradiciones morales que recuperan el papel del corazón de tradición bíblica en la ética social. Cfr. R. BELLAH y otros: Hábitos del Corazón. Alianza, Madrid 1985; R. WuTHNOW: Actos de compasión. Cuidar de los demás y ayudarse a sí mismo, Alianza, Madrid 1996; H. BÉJAR: El mal samaritano. El altruismo en tiempos de escepticismo. Anagrama, Barcelona 2001. 
reducir los fundamentos de la ética social a su dimensión contractual y jurídica. Una tradición plural en la que tienen cabida desde cierto socialismo liberal hasta el comunitarismo o la socioeconomía ${ }^{6}$.

\section{Usos y abusos de la ética}

Los vaivenes de la privatización están relacionados con la instrumentalización de la ética social, algo que en la encíclica de Benedicto XVI podemos describir como «usos y abusos de la ética». No en vano utiliza el término «quicio» para describir la necesidad de buscar el punto exacto, el equilibrio entre derechos y deberes cuando queremos tomar en serio el desarrollo $\left(n^{\circ} 43\right)^{7}$. La encíclica denuncia el abuso del término «ética» en el campo económico y empresarial. En el $\mathrm{n}^{\circ} 45$ aparece la siguiente expresión: «se nota un cierto abuso del término 'ético' que, usado de manera genérica, puede abarcar también contenidos completamente distintos, hasta el punto de pasar por éticas decisiones y opciones contrarias a la justicia y al verdadero bien del hombre».

No sólo deberíamos lamentar el abuso, sino celebrar la actualidad de la ética en los espacios de investigación científica y deliberación pública. Una actualidad a la que se ha contribuido desde centros educativos y de investigación identificados con la Iglesia y desde la que se debe plantear una doble responsabilidad. Aunque se ve muy claro esta lamentación por el abuso, también hay una celebración de la actualidad de la ética cuando en el $\mathrm{n}^{\circ} 45$ se afirma: «Sus efectos positivos llegan incluso a las áreas menos desarrolladas de la tierra».

Un quicio que falta en la ética contemporánea cuando parte de la separación entre verdad y justicia. Desde hace casi cuatro décadas, el pensamiento político ha separado de manera supuestamente nítida los campos de la verdad y la justicia. Sin que John Rawls lo hubiera planteado de manera contradictoria, sus intérpretes siempre tuvieron claro que las primeras páginas de su Teoría de la justicia dejaban

6 Cfr. C. DíAz: Soy amado, luego existo. I, II, III. Desclée, Bilbao 1999-2003; A. Cortina: Alianza y Contrato, Trotta, Madrid 2004. Un primer acercamiento a la socioeconomía puede encontrarse en J. PÉREZ ADÁN (coord.), "Socioeconomía", número monográfico Revista Anthropos, 188 (2000). Sobre la génesis, evolución e impacto en la ética pública del voluntariado, puede verse nuestro trabajo Ética y Voluntariado. Una solidaridad sin fronteras, PPC, Madrid 2001.

A partir de ahí elaboré un primer comentario que presenté en las Aulas del Instituto Emmanuel Mounier y que salió publicado con el título "De cómo sobrevivir a una civilización desquiciada", Acontecimiento, 93 (2009), 47-53. Una versión anterior de este artículo llevaba por título "Ética Económica y nuevo management. La reinvención de la economía con inteligencia diligente", Corintios XIII, 132 (2009), 107-125. 
nítidamente separados los campos de la verdad y la justicia. En ellas decía: «La justicia es la primera virtud de las instituciones sociales, como la verdad lo es de los sistemas de pensamiento».

Esta analogía sentó las bases para que el pensamiento político posterior no sólo plantease como alternativos lo justo y lo bueno ${ }^{9}$, sino para que algunos pensadores postmodernos de la política plantearan la prioridad de la Democracia sobre la Filosofía ${ }^{10}$. Este es el importante planteamiento de Rorty que legitima no sólo la separación entre justicia/verdad o democracia/filosofía, sino también la escisión entre ciudadanía/filosofía. En este contexto todo intento de unir caridad y verdad no sólo se presenta como titánico sino como revolucionario y contracultural.

\section{Lógica de la equivalencia y lógica de la donación}

Un intento semejante ha sido realizado por la ética filosófica de Paul Ricoeur en sus trabajos sobre la ética narrativa, el perdón y la justicia. No podemos detallar con precisión el impacto de los postulados de Ricoeur en la encíclica de Benedicto XVI, pero sí pueden rastrearse expresiones que han permanecido de los primeros textos elaborados por buenos conocedores de la fenomenología, la hermenéutica y el personalismo, porque expresiones como las de «donación», «economía del don»o «lógica de la sobreabundancia» son propias de la mejor tradición fenomenológica que representa Ricoeur.

Podemos remitirnos a sus primeros escritos recogidos en Historia y Verdad donde ya aparece la donación a través de gestos de coraje, de testimonios y de prácticas de perdón o entrega generosa. Incluso leerlo conjuntamente con E. Lévinas o J. L. Marion cuando reconstruyen la fenomenología con las categorías de «reducción»y «donación» ${ }^{11}$. Pero lo

8 J. RAWLS: Teoría de la justicia. FCE, Madrid 1979, 19.

9 Alternativa denunciada en el número monográfico dedicado a Rawls por la Revue de Metaphysique et Morale, 93 (1988), 33-56, donde Charles Taylor recupera la relación en su artículo "Le juste et le bien", o en todos los trabajos de Paul Ricoeur donde reivindica la pluralidad de instancias de la justicia o la estrecha relación entre el amor y la justicia. Cfr. Amor y Justicia, Caparrós editores, Madrid 1993 (Traducción Tomás Domingo); o Lo Justo I, Caparrós-Instituto Emmanuel Mounier, 1999 (Traducción A. Domingo), y Lo Justo II, Trotta, Madrid 2008 (Trad. T. y A. Domingo).

10 R. RORTY publicó un artículo que llevaba por título "La prioridad de la democracia sobre la Filosofía", en el colectivo editado por G. Vattimo: La secularización de la Filosofía. Gedisa, Barcelona 1999.

11 Cfr. E. Levinas: Ethique comme philosophie première. Payot, Paris 1992; J. L. MARION: Réduction et Donation. PUF, Paris 1989. 
realmente sorprendente es el texto de 1990 que elabora cuando le conceden el Premio Hegel y que lleva por título «Amor y Justicia».

Las palabras de Ricoeur están elaboradas para mostrar que los actos de amor y generosidad pueden ser filosóficamente planteados como actos en los que emerge un «exceso» de una gran productividad para la justicia, exceso que representa una lógica de la sobreabundancia de un orden supra-ético que permite ensanchar, corregir y abrir la lógica de la equivalencia. En palabras del propio Ricoeur: "La economia del don desborda por todas las partes a la ética (...) El amor al prójimo, bajo su forma extrema de amar a los enemigos, encuentra en el sentimiento supra-ético de la dependencia del hombre-criatura su primer vínculo con la economía del don (...) La economía del don desarrolla una lógica de la sobreabundancia que, en un primer momento al menos, se opone polarmente a la lógica de la equivalencia que gobierna la ética cotidiana (...) La tensión no equivale a la supresión del contraste entre las dos lógicas (...) por el contrario, hace de la justicia el medio necesario del amor» ${ }^{12}$.

Un planteamiento interesante con el que se enfrenta y salva a John Rawls. Se enfrenta, porque denuncia el olvido del bien y el amor en una teoría de la justicia; pero salva a Rawls, porque éste no cae totalmente en las redes del utilitarismo. "Lo que salva al segundo principio de justicia de Rawls de una recaida en el utilitarismo sutil es su proximidad secreta con el mandato del amor (...) Este parentesco es uno de los presupuestos no dichos del famoso equilibrio reflexivo(...)» ${ }^{13}$. Recordemos en este contexto el $\mathrm{n}^{\circ} 34$ donde Benedicto XVI afirma: "(...) Por su naturaleza, el don supera al mérito, su norma es sobreabundar (...) la lógica del don no excluye la justicia ni se yuxtapone a ella como un añadido externo (...)».

\section{Cambios en ética social: globalización, deliberación y donación}

La desprivatización de la caridad permite plantear una renovación de la ética social como ética de la vida social o vida pública en su sentido más amplio. A diferencia de ciertas interpretaciones de la modernidad y del liberalismo que mantienen separadas la esfera privada y la esfera pública de la vida humana, la encíclica refuerza la tradición de la moral social católica donde la ética social se identifica con la ética de la vida pública en su sentido más amplio. De esta forma se evita la confusión

12 P. Ricoeur: Amor y Justicia, 27-33. Una contextualización precisa de este texto puede encontrarse en nuestro trabajo "Ética civil y gratuidad. El personalismo narrativo de Paul Ricoeur", en VV.AA., La pregunta por la ética. UPSA; Salamanca 1993, 57-82. El trabajo citado de J. D. CAUSSE: El don del agapé, desarrolla esta complementariedad en el segundo capítulo que llama "El movimiento del don", 37 ss.

13 Ibíd. 
entre «ética social» o «ética pública» en su sentido más general, y «ética política». Una confusión excesivamente usada por quienes participan de un modelo de sociedad tutelada o dirigida por las administraciones públicas o los dirigentes políticos.

Este planteamiento de ética social es importante para fortalecer un concepto de sociedad civil abierta a los desafíos de las instituciones políticas $y$, a su vez, promotora de una ciudadanía activa en todas sus dimensiones. Un planteamiento que incrementa el valor que la iglesia concede a la sociedad civil sin restar un ápice a las responsabilidades propias de las administraciones públicas o las personas. Se ensanchan las dimensiones de la sociedad civil que en la era de la información es necesariamente global, se promueve la necesidad de marcos de referencia moral que faciliten la deliberación pública y se legitima la presencia social de la donación.

\section{Globalización: horizonte de responsabilidad social}

La globalización ha cambiado totalmente las coordenadas de la ética social. La encíclica concede carta de naturaleza a problemas morales que antes corrían el peligro de ser tangenciales o marginales a la economía como el mundo de la gratuidad y donación. En la propia introducción hay una referencia explícita a una globalización que es calificada como «progresiva y expansiva»: «El riesgo de nuestro tiempo es que la interdependencia de hecho entre los hombres y los pueblos no se corresponda con la interacción ética de la conciencia y el intelecto, de la que pueda resultar un desarrollo realmente bumano» $\left(\mathrm{n}^{\circ}\right.$ 9).

Desde la aparición de la Populorum progressio, la novedad principal ha sido «el estallido de la interdependencia planetaria». Aunque haya surgido en los países económicamente desarrollados, «ha implicado por su naturaleza a todas las economías», «ha sido el motor para que regiones enteras superaran el subdesarrollo y es, de por sí, una gran oportunidad». Inmediatamente, la encíclica plantea un «pero» a este proceso de globalización para que no se convierta en una nueva versión del desarrollismo o simple ideología instrumental (globalismo). Sin la guía de la caridad en la verdad, este impulso puede contribuir a crear riesgo de daños hasta ahora desconocidos y nuevas divisiones en la familia humana.

La globalización tiene una dimensión teológica incuestionable: «es un fenómeno multidimensional y polivalente, que exige ser comprendido en la diversidady en la unidad de todas sus dimensiones, incluida la teológica. Esto consentirá vivir y orientar la globalización de la bumanidad en términos de relacionalidad, comunión y participación» ( $\mathrm{n}^{\circ} 42$ ). Aunque son muchas las exigencias que plantea, destacamos las siguientes: 
a. La vergüenza del hambre que genera inseguridad. En la era de la globalización. Eliminar el hambre en el mundo se ha convertido en una meta para salvaguardar la paz y la estabilidad del planeta. El hambre no depende tanto de la escasez material (hay bienes primarios para todos), cuanto de la insuficiencia de recursos sociales, «el más importante de los cuales es de tipo institucional. Es decir, falta un sistema de instituciones económicas capaces (...)» $\left(n^{\circ} 27\right)$. No sólo son urgentes la alimentación y el acceso al agua como derechos universales sino la sostenibilidad a largo plazo y el mantenimiento de «la vía solidaria hacia el desarrollo». Una vía donde la meta no está en el mantenimiento de las politicas de dependencia sino la promoción de políticas de responsabilidad para que los mismos países pobres puedan satisfacer las necesidades de bienes de consumo y desarrollo de los propios ciudadanos ( $\left.n^{\circ} 27\right)$.

b. La reforma ética del sistema financiero. La encíclica constata la mala utilización de la economía financiera que ha dañado la economía real. No sólo son útiles sino indispensables iniciativas financieras en las que predomine la dimensión humanitaria (microcréditos, microfinanzas). Sin embargo, Benedicto XVI no se limita a celebrar estas iniciativas de reforma llevadas a cabo con pretensiones humanitarias. Pide que todo el sistema financiero tenga como meta el sostenimiento del verdadero desarrollo, pide que los agentes «redescubran» el fundamento ético de su actividad para no abusar de los instrumentos sofisticados con los que se puede fácilmente traicionar a los ahorradores. En el campo de crédito cooperativo, en las cajas de ahorro, en los Montes de Piedad hay experiencias éticas a tener en cuenta. Las microfinanzas es una experiencia útil para todos los países. La educación ética no puede prescindir de esta dimensión y formar a los más débiles y pobres no sólo para la utilización de estos recursos financieros sino para defenderse de la usura. Un dato importante en este contexto es la reclamación de la responsabilidad del ahorrador $\left(n^{\circ} 65\right)$.

c. La posibilidad real de una autoridad politica mundial. Idea importante en la que ya había insistido Juan Pablo II y que aparece como transición entre la quinta parte (colaboración familia humana) y la sexta (desarrollo y técnica). Ante la 
necesidad de reformar las Naciones unidas y la arquitectura económico-financiera, urge promover formas innovadoras que pongan en práctica el principio de la responsabilidad de proteger y dar una voz eficaz en las decisiones comunes a la voz de los más pobres. Esta autoridad no sólo deberá estar regulada por el derecho, o deberá atenerse a los principios de subsidiariedad y solidaridad, o deberá buscar el bien común, comprometerse en la realización de un desarrollo integral basado en «los valores de la caridad en la verdad», sino que deberá estar reconocida por todos y gozar de poder efectivo. El desarrollo integral y la colaboración internacional reclaman unn grado superior de ordenamiento internacional de tipo subsidiario para el gobierno de la globalización». Aunque su exigencia parece novedosa, en realidad no lo es porque ya está previsto en el Estatuto de las Naciones Unidas ( $n^{\circ} 67$ ).

\section{Deliberación: necesidad de un marco de referencia moral}

La globalización exige responsabilidad que podríamos calificar como prudencial, hay que ser diligentes y tener cuidado con el entusiasmo y la ilusión desarrollista que genera la interdependencia planetaria. También hay que evitar el fatalismo de una globalización determinista que anula la responsabilidad moral de personas y los pueblos. Quienes plantean la globalización en términos deterministas y fatalistas pierden criterios para valorarla y orientarla $\left(\mathrm{n}^{\circ} 42\right)$. Ante posiciones basadas ante la ingenuidad o negligencia por las consecuencias de la globalización, la encíclica reclama una responsabilidad prudencial que exige «ensanchar la razón y hacerla capaz de conocer y orientar estas nuevas e imponentes dinámicas, animándolas en la perspectiva de esa civilización del amor». ( $\left.n^{\circ} 33\right)$. Esto será lo que permita corregir sus disfunciones.

Introduce un concepto importante en todo proceso de deliberación: la necesidad no sólo cognitiva sino existencial y antropológica de un «sistema de referencia moral». La ética social no es una disciplina originada por sí misma o cerrada en sí misma, forma parte de una filosofía de vida, de un sistema de creencias, de una cosmovisión, de una metafísica o, simplemente, de un «sistema de referencia». Para los católicos, la doctrina social de la iglesia actúa de sistema de referencia y facilita dos pilares para construir una ética económica: la creación del hombre a imagen de Dios y el valor trascendente de las normas morales naturales. La deliberación se aplica en tres direcciones: 
a. La renovación de una inteligencia diligente, no menos importante es el papel de la razón y la inteligencia humana para afrontar las desviaciones y problemas dramáticos del desarrollo. Aquí emerge la urgente necesidad no sólo del trabajo interdisciplinar sino del acercamiento al ser humano como especie que no puede prescindir de su propia naturaleza. La globalización está en el centro de una comprensión unitaria y una «nueva síntesis humanista». Ante la complejidad y la gravedad la mejor receta es el realismo, la confianza y la esperanza. Las políticas migratorias, tecnológicas, financieras y energéticas no pueden plantearse aisladamente: «Las fuerzas técnicas que se mueven, las interrelaciones planetarias, los efectos perniciosos sobre la economía real de una actividad financiera mal utilizada y en buena parte especulativa, los imponentes flujos migratorios, frecuentemente provocados y después no gestionados adecuadamente, o la explotación sin reglas de los recursos de la tierra, nos induce boy a reflexionar sobre las medidas (...) que tienen un efecto decisivo para el bien presente y para el futuro de la bumanidad» $\left(\mathrm{n}^{\circ} 21\right)$.

b. El nuevo poder de los consumidores y sus organizaciones. Por primera vez en una encíclica se plantea explícitamente la aparición de este poder con alcance político y económico pero de naturaleza radicalmente social. El consumidor tiene una responsabilidad social específica que se añade a la responsabilidad social de la empresa. Con su cara y su cruz. «Comprar es siempre un acto moral, no sólo económico» $\left(n^{\circ}\right.$ 66). Ya que se ejercita diariamente, conviene estar formado, y se puede expresar en la creación de cooperativas de consumo, en la creación de formas nuevas de comercialización de productos $y$ en estilos de consumo caracterizados por la sobriedad. La encíclica pide que los consumidores estén más formados para ejercer la responsabilidad social en el mundo de la economía, y para evitar su manipulación por asociaciones de consumidores poco representativas. Los consumidores son «un factor de democracia económica» (n. 66).

c. La renovación ética de la autoridad y el poder político de los estados: «el estado se encuentra con el deber de afrontar las limitaciones que pone a su soberania el nuevo contexto económico-comercial y financiero internacional, caracterizado también por una creciente movilidad de los 
capitales financieros $y$ de los medios de producción materiales $e$ inmateriales. Este nuevo contexto ha modificado el poder politico de los estados» ( $\mathrm{n}^{\circ}$ 24) La modificación de la responsabilidad política de los estados no se realiza para minimizar o maximizar su papel ante el mercado, sino para organizarse en términos de justicia social y bien común. En el no 41 la advertencia es clara: «La sabiduría y la prudencia aconsejan no proclamar apresuradamente la desaparición del Estado (...) hay naciones donde la construcción o reconstrucción del estado sigue siendo un elemento clave para el desarrollo». La ayuda al desarrollo no está para mantener la dependencia sino que debería «apoyar en primer lugar la consolidación de los sistemas constitucionales, jurídicos y administrativos en los países que no gozan plenamente de estos bienes (...) no es necesario que el estado tenga las mismas características en todos los sitios».

\section{Donación: opción por una antropología integral}

La globalización y la deliberación son necesarias, pero insuficientes: «la vocación misma al desarrollo de las personas y de los pueblos no se fundamenta en una simple deliberación humana (...)» ( $\left.\mathrm{n}^{\circ} 52\right)$. Voy a utilizar el término «donación» para incidir en una dimensión básica y antropológica de la caridad. Soy consciente que el término caridad es más amplio porque no describe únicamente el amor recibido sino también el amor ofrecido. Utilizo el término para describir la dimensión que antes he llamado de gratuidad-donación siendo consciente que tan importante como la dimensión activa (dar) es la dimensión pasiva (recibir), una idea que también está presente cuando releemos la filosofía moral contemporánea desde los Caminos del reconocimiento ${ }^{14}$.

Esta dimensión antropológica supone la recuperación de una dimensión intrínseca de la responsabilidad personal que no siempre queda clara cuando hablamos de la responsabilidad social. Me estoy refiriendo a la implicación de la persona como tal, no sólo en función de cada una de las dimensiones o actividades de su vida social. En la encíclica se recupera esta implicación personal cuando se hace referencia a la totalidad de la persona, a todas sus dimensiones, y cuando se nos recuerda que las instituciones por sí solas no bastan, que son necesarias

14 Cfr. P. Ricoeur: Caminos del reconocimiento. Trotta, Madrid 2004. En este contexto es interesante el trabajo de T. Domingo: "Del sí mismo reconocido a los estados de paz. Caminos de hospitalidad en Paul Ricoeur”, Pensamiento 62 (2006), 203-230. 
pero no suficientes. Con ello no sólo se recupera una dimensión biográfica de la persona sino que se apela a una vinculación biológica.

Esta relación nos ayuda a evitar los reduccionismos antropológicos a los que hace referencia la encíclica en el $n^{\circ} 76$ y que, a la vez, hace comprensible la inclusión de la bioética en una reflexión sobre el desarrollo integral. Además, nos ayuda a entender una afirmación que es central en la encíclica: «la cuestión social se ha convertido en una cuestión antropológica» ( $\left.\mathrm{n}^{\circ} 75\right)$. Hay una serie de nuevas coordenadas antropológicas sin las cuales será difícil entender la renovación de la ética económica y de las organizaciones. Algunas de estas coordenadas son las siguientes:

a. Debemos hacer memoria de que el primer capital es el capital bumano. En situaciones de crisis y ajustes económicos en los que la movilidad de capitales y des-regulación de los mercados puede des-humanizar la economía es fundamental afirmar lo siguiente: «el primer capital que se ha de salvaguardar y valorar es el hombre, la persona en su integridad» $\left(\mathrm{n}^{\circ} 25\right)$. Esto no significa que el trabajador y el trabajo sean descritos en términos materiales como «capital». En el lenguaje de la economía, el mundo del trabajo y los trabajadores suele ser descrito en términos de capital bumano, a diferencia del mundo social que es descrito como capital social, el mundo económico-financiero como capital financiero, y los recursos naturales como capital físico. De hecho, la encíclica no hace estas referencias para separar la razón moral de la razón económica sino para plantear con radicalidad el sentido de la economía y sus fines, para tener siempre presente que los costes humanos son siempre costes económicos. Cuando aumenta la pobreza no sólo se tiende a erosionar la cohesión social y se pone en peligro la democracia, sino que se produce un impacto negativo en el plano económico "por el progresivo desgaste del 'capital social', es decir, el conjunto de relaciones de confianza, fiabilidad y respeto de las normas, indispensables para toda convivencia civil» $\left(\mathrm{n}^{\circ} 33\right)$.

b. Luchar contra la «corrosión del carácter», en expresión de R. Sennet ${ }^{15}$. Cuando la globalización corre el peligro de reducir el trabajo

15 R. SennetT: La corrosión del carácter. Anagrama, Madrid 2000. Sennett reivindica siempre la necesidad de un marco narrativo para que los trabajadores no sólo busquen 
humano al mercado y exige aceptar con resignación e impotencia la reducción o supresión de las redes de seguridad social que se empezaban a poner en marcha, entonces se deshumaniza el trabajador y sus condiciones laborales. Aunque la movilidad laboral puede estimular la producción de nueva riqueza e incluso favorecer el intercambio de culturas: «(...) cuando la incertidumbre sobre las condiciones de trabajo a causa de la movilidad y la desregulación se hace endémica, surgen formas de inestabilidad psicológica, de dificultad para crear caminos propios coherentes en la vida, incluido el del matrimonio (...) el estar sin trabajo o la dependencia prolongada (...) mina la libertad y la creatividad de la persona y sus relaciones familiares y sociales, con graves daños en el plano psicológico $y$ espiritual» ( $\mathrm{n}^{\circ}$ 25). En la tradición personalista esta lucha contra el fatalismo y la deshumanización se ha planteado genéricamente desde el humanismo cristiano y explícitamente desde «una orientación cultural personalista y comunitaria, abierta a la trascendencia, del proceso de integración planetaria» $\left(\mathrm{n}^{\circ}\right.$ 42). En este contexto, el mundo del trabajo no puede dar la espalda ni al mundo de la familia ni al mundo del matrimonio. El compromiso por la familia y la vida, que se traduce en estrategias de conciliación de la vida familiar y laboral, o en estrategias de protección de la maternidad o la vida matrimonial no son sólo necesidades sociales sino necesidades económicas. La apertura a la vida es mucho más que una pretensión moral o teológica, es «una riqueza social y económica» $\left(\mathrm{n}^{\circ} 44\right)$.

c. El reduccionismo del hombre a mero dato cultural, y el consiguiente desconcierto ante la nueva relación entre naturaleza y cultura. Benedicto XVI deja constancia de una diferencia importante entre la situación cultural que vivió Pablo VI y la que vive él. Antes las culturas estaban bien definidas y tenían posibilidades de defenderse ante los intentos de

la coherencia personal sino que sean capaces de ser auténticos, fiables y fieles a sí mismos. Las antropologías modernas no siempre facilitan este marco narrativo y por ello apela a las antropologías de Gadamer, Levinas o Ricoeur para reclamar una antropología narrativa que evite la dispersión del yo, el atomismo, la fragmentación personal y la corrosión del carácter. Critica un sistema económico y político mercantilizado porque «(...) cuando un régimen no proporciona a los seres humanos ninguna razón profunda para cuidarse entre sí no puede preservar durante mucho tiempo su legitimidad» (p. 155). 
homogeneización. Hoy, la interacción ha aumentado, abriéndose nuevas posibilidades para el diálogo intercultural, sin embargo, asistimos a la progresiva mercantilización cultural. Algo que observamos en un eclecticismo cultural que se asume de manera acrítica, lo que induce a caer en el relativismo cultural. Este relativismo «provoca que los grupos culturales estén juntos o convivan, pero separados, sin diálogo auténtico $y$, por lo tanto, sin verdadera integración. Existe (...) el peligro opuesto de rebajar la cultura y homologar los comportamientos y estilos de vida (...) perdiendo el sentido profundo de la cultura de las diferentes naciones, de las tradiciones de los pueblos, en cuyo marco la persona se enfrenta a las cuestiones fundamentales de la existencia». Así, tanto el eclecticismo como el bajo nivel cultural coinciden en separar la cultura de la naturaleza $\left(\mathrm{n}^{\circ} 26\right)$.

\section{El lugar de la caridad en la ética empresarial}

Hace algunos años resultaba sorprendente hablar de ética empresarial, no faltaban filósofos o empresarios que ridiculizaban el término amparándose en la analogía del agua y el aceite ${ }^{16}$. Han tenido que pasar varios años y crisis para reconocer la necesidad y urgencia tanto de una ética económica como de una ética empresarial. Igual que hace unos años resultaba sorprendente hablar de ética empresarial hoy resulta sorprendente que nos preguntemos por el lugar de la caridad en la ética empresarial. No es habitual hacerlo cuando se tienen visiones poco amplias y realistas de la gestión empresarial. Si ya costó mucho reconocer el valor de un enfoque realista para plantear la necesidad de una ética empresarial, también está costando mantenerse despiertos para comprobar la pluralidad de sistemas de referencia moral y, por consiguiente, la posibilidad de que haya algunos que no excluyan a priori la caridad.

La encíclica de Benedicto XVI no obliga a contar con la caridad en los modelos de ética económica y empresarial. Las reflexiones que ofrece son interesantes, atractivas y opcionales, lo que no resta un ápice a que sean también realistas porque describen la complejidad de la globalización, la responsabilidad social y la gestión empresarial. A diferencia de algunas que dejan la caridad fuera del sistema económico, o

16 Cfr. A. Cortina, J. Conill, A. Domingo, D. García: Ética de la empresa. Claves para una nueva cultura empresarial. Trotta, Madrid 1995, $8^{\text {a }}$ ed. Es clarificador el trabajo del profesor J. ConilL: Horizontes de Economía Ética. Tecnos, Madrid 2004. 
de otras que lo integran y la sitúan dentro de la liberalidad del empresario, la encíclica concede a la caridad una función primordial. En cualquier caso, es incuestionable que hoy el conjunto de la actividad económica y empresarial está obligado a contar con factores que si no son identificados como «caridad» sí lo son como «solidaridad» ${ }^{17}$.

¿Por qué excluirla si los modelos de empresa cada vez son más complejos? ¿Por qué excluirla si están surgiendo nuevos modelos organizativos de empresa? ¿Acaso el Tercer Sector y las organizaciones sin ánimo de lucro no integra modelos de gestión que no excluyen la caridad ${ }^{18} \mathrm{La}$ encíclica ofrece una posibilidad realista de integrar la caridad dentro de un modelo amplio de ética económica y empresarial como el que se ha construido desde la doctrina social de la iglesia. No voy a precisar con detalle cuáles serían sus antecedentes, pero sí voy a indicar algunas aportaciones que realiza el texto de Benedicto XVI para renovar la reflexión sobre la gestión empresarial (management) ${ }^{19}$.

Voy a utilizar la expresión «nuevo management» (NM) para describir la aportación que se realiza en la encíclica a la teoría de la dirección, gestión y administración de la empresa ${ }^{20}$. Aunque aparezcan elementos que puedan completar esta teoría del NM en otros puntos de la encíclica, me voy a fijar en el análisis de las ideas centrales que, a mi juicio, aparecen entre los números 34 y 52. Si tuviera que elegir uno para explicar esta novedad empezaría por el $n^{\circ} 40$, donde quiero llamar la atención ante la importancia que Benedicto XVI concede a los cambios profundos en el modo de entender la empresa y la necesidad de pensar la figura profesional del manager de una manera diferente. Con tres objetivos principales: conducir personas con responsabilidad social, atender al proceso para generar valor y dirigir organizaciones con racionalidad cordial.

17 Cfr. S. Rose-ACKerman: "Altruism non profit and economic theory", Journal of Economic Literature, 34 (1996), 701-728; L. A. GERARD-VARET et al.: The economic of reciprocity, diving and altruism, Macmillan, London 2000; M BISHOP and M. GREEN: Philanthrocapitalism: How the rich can save the world. AC Black, New York 2008.

18 En 1993 la Universidad de Harvard lanzó el programa Social Enterprise Initiative; en 2002 el Reino Unido publicó el documento Social Enterprise: A Strategy for Sucess. Para un estudio detallado de estos nuevos modelos organizativos de empresa, cfr. P. VECIANA BОTET (coord.): Las empresas de inserción en España. Fundación Unsolmon, Barcelona 2007.

19 Sobre la contribución de la Doctrina Social de la Iglesia al desarrollo de una economía altruista, véase el interesante trabajo del profesor E. LLUCH: Por una economía altruista. Apuntes cristianos de comportamiento económico. PPC, Madrid 2010.

20 Cfr. R. E. Freeman: Strategic management: A Stakeholder Approach. Pitman, Boston 1991. 


\section{Conducir personas con responsabilidad social}

Benedicto XVI no se ha limitado a dejar constancia sobre la importancia que hoy tienen en la Ética económica y empresarial las estrategias de responsabilidad social de la empresa. Además afirma: «(...) no todos los planteamientos éticos que guian hoy el debate sobre la responsabilidad social de la empresa son aceptables según la perspectiva de la doctrina social de la iglesia» ( $\mathrm{n}^{\circ}$ 40). Ciertamente, la responsabilidad social de la empresa apunta un cambio importante que es necesario: «(...) la gestión de la empresa no puede tener en cuenta únicamente el interés de sus propietarios sino de todos los otros sujetos que contribuyen a la vida de la empresa: trabajadores, clientes, proveedores de los distintos elementos de producción, la comunidad de referencia (...)» ( $\left.\mathrm{n}^{\circ} 40\right)$. Ahora bien, el sistema de referencia moral que se plantea para el conjunto de la ética social y política tiene consecuencias importantes para la ética económica y empresarial $^{21}$.

El NM no es el resultado de una aplicación instrumental y mecánica del sistema de referencia moral que se describe en la encíclica al campo de las actividades empresariales y organizativas. El NM no se limita a aplicar al campo de la economía o las organizaciones lo que se ha construido previamente en el campo de la teología moral. El NM no es un fruto residual de la nueva ética social, sino que desempeña un papel central en ella. El mundo de la economía y la empresa no son mundos construidos al margen de la vida moral de las personas y en los que, en un segundo momento, intervienen los principios morales para corregirlos o rectificarlos. La encíclica nos recuerda que la ética en general y los sistemas de referencia morales no son extrínsecos a la actividad económica o empresarial sino que son intrínsecos a ella misma.

El NM puede plantearse como el desarrollo extrínseco de la ética en el campo organizativo. Puede plantearse dentro de la exigencia cada día más apremiante de que la economía tiene necesidad de la ética para su correcto funcionamiento ${ }^{22}$. Puede plantearse dentro de las estrategias de la business ethics, de las certificaciones éticas, de las finanzas éticas, de las microfinanzas y de toda la nueva cultura ética generada por la

21 Cfr. T. M. JONES: “Corporate Social Responsability Revisited, Redefined": California Management Review, 22 (1980), 59-67.

22 Este «Nuevo Management» continúa la tradición de lo que técnicamente llamamos Management estratégico porque no se limita a la inmediatez del corto plazo (táctica), ni a las propuestas estrictamente técnicas de gestión, y menos aún a la instrumentalización de las personas que intervienen en la empresa. Esta forma de gestión es creativa, conceptual, integradora y holística. Cfr. I. DEL VAL: Management Estratégico. Esic, Madrid 2005; C. KLuYver: Pensamiento estratégico. Prentice Hall, Buenos Aires 2001. 
responsabilidad social empresarial. Ahora bien, en estos ámbitos hay que elaborar un criterio de discernimiento, pues «se nota un cierto abuso del adjetivo ético que (...) puede abarcar contenidos completamente distintos, hasta el punto de hacer pasar por éticas decisiones y opciones contrarias a la justicia y el verdadero bien del hombre» ( $\left.\mathrm{n}^{\circ} 45\right)$. El criterio de discernimiento no está en «lo ético», entendido como adjetivo, sino en el «sistema moral de referencia».

De este forma podemos dejar de «recurrir a la palabra ética de una manera ideológicamente discriminatoria, dando a entender que no serían éticas las iniciativas no etiquetadas formalmente con esta cualificación» $\left(n^{\circ} 45\right)$. Sin un sistema moral de referencia no disponemos de criterio de validación para discriminar entre un uso correcto e incorrecto, entre el uso legítimo y el abuso cosmético del término «ética». Lo importante no es que aparezcan sectores, segmentos o incluso estilos adjetivados como «éticos». Lo importante es que «toda la economía y las finanzas sean éticas y lo sean no por una etiqueta externa sino por el respeto de exigencias intrínsecas de su propia naturaleza» $\left(n^{\circ} 45\right)$. Esto es lo que nos puede permitir distinguir entre una responsabilidad social funcional (ética como ajuste) y una responsabilidad social critica (ética como origen y meta, sistema de referencia).

\section{Atender corresponsablemente los procesos para generar valor}

La encíclica rompe con el uso instrumental y funcional de la responsabilidad social, es decir, con la tendencia habitual a segmentar la responsabilidad social fuera de las actividades y procesos empresariales. Frente a una derivación de la responsabilidad social hacia fundaciones, obras sociales o acciones filantrópicas extrínsecas a los procesos de generación de valor, Benedicto XVI sugiere un modelo de gestión que atienda todos los procesos y momentos de la actividad empresarial. Esto exige nuevos perfiles de directivos que organicen los procesos no sólo en términos de beneficio sino en términos de virtud.

Mientras que la economía neoclásica y neoliberal plantea la responsabilidad social como consecuencia del beneficio y la rentabilidad, Benedicto XVI marca distancias con estos modelos para mostrar que la responsabilidad social no es una exigencia que nace del beneficio conseguido sino del valor intrínseco a las actividades empresariales. La responsabilidad social no es una preocupación o exigencia derivada del interés crematístico de la empresa sino de la legitimidad social de la organización. De esta forma, la responsabilidad social implica a todos los afectados por la actividad de la empresa (stakeholders) adquiriendo en la encíclica un valor normativo. 
La actuación socialmente responsable no es un elemento más dentro del cálculo económico de utilidades sino un factor intrínseco a la generación de riqueza, beneficio o valor que quieran ser éticos. Frente al utilitarismo y el relativismo, «No se trata de un simple cálculo económico de la actuación socialmente responsable sino de la contribución al desarrollo y a la riqueza desde una preocupación por las consecuencias producidas durante el mismo proceso de generación del beneficio, entendiendo este como medio y no como fin» ${ }^{23}$.

\section{Dirigir organizaciones con razón cordial}

Durante las últimas décadas se ha producido una revolución importante en la ética social que ha permitido la recuperación del adjetivo «cordial» para describir el nuevo modelo de racionalidad que integra la caridad ${ }^{24}$. Una revolución que ha afectado no sólo a la forma de concebir las relaciones entre solidaridad y justicia sino a las formas tradicionales de entender la empresa y el mundo organizativo ${ }^{25}$. Esta era la puerta por la que entraban las reivindicaciones de la ética de la solidaridad al mundo de la economía y la política, entendidos estos de manera restringida.

En los textos de Juan Pablo II la Economía de la gratuidad y la cultura de la solidaridad se hacían presentes en el mundo económico y el mundo político desde el mundo de la sociedad civil. Tradicionalmente hablábamos de tres instancias: el mercado, el estado y la cultura (sociedad civil). En este esquema de interpretación las iniciativas de caridad, de solidaridad y de gratuidad entraban por la puerta de la cultura. Conquistaban progresivamente el espacio del estado o del mercado, pero no lo hacían desde dentro de las actividades políticas o económicas. Entraban desde actividades filantrópicas, eran externas o tangenciales a la economía y la política, pero no intrínsecas y consustanciales a dichas actividades.

Esta delimitación de ámbitos corría el peligro de convertirse en una simplificación de funciones que no respondía a la realidad. El propio concepto de «organización no gubernamental» describe a organizaciones

\footnotetext{
23 R. ARAQUE: "Empresa y Sociedad en la CiV", Revista de Fomento Social, 256 (2009), 679-686, p. 684.

24 Cfr. C. DíAz: Filosofía de la razón cordial. Editorial Mounier, Córdoba-Argentina 2005; A. CorTinA: Ética de la razón cordial. Nobel, Oviedo 2008; Justicia cordial, Trotta, Madrid 2010.

25 Sobre el papel del Voluntariado en estas transformaciones puede verse nuestro estudio Ética y Voluntariado. Una solidaridad sin fronteras, PPC, Madrid 2000, $2^{a}$ edición, especialmente capítulos 3-5.
} 
que necesitan autorización o inscripción pública o legal (estado), que realizan actividades económico-mercantiles, que dan puestos de trabajo y que acogen actividades que generan riqueza o beneficio (mercado) y que se organizan de manera informal con criterios donde la solidaridad o donación de sí desempeña un papel importante (cultura). Ante esta situación la encíclica pide que evitemos la simplificación y plantea la necesidad de reconocer la pluralidad de formas institucionales de empresa. Deja constancia de la aparición de una zona intermedia que no es estrictamente ética (en el sentido tradicional restringido) y que no es estrictamente empresa (en el sentido tradicional restringido). Aquí están empresas convencionales que suscriben pactos con países atrasados, fundaciones, grupos de empresas que tienen objetivos de utilidad social y agentes de la economía civil y de comunión.

La gestión empresarial no es un saber axiológicamente neutral, sino que depende de los sistemas de referencia moral ( $\left.n^{\circ} 36\right)$. El sistema de referencia al que nos invita la encíclica facilita propuestas interesantes para dirigir organizaciones con razón cordial.

a. Justicia y Solidaridad son inseparables. Si antes se pensaba que la Economía producía la riqueza y la Política la distribuía, hoy el planteamiento no puede ser tan reduccionista y simplificador. Las tendencias de la economía contemporánea donde lo local y lo global intervienen de manera tan directa exigen que la justicia sea pensada de una manera más radical. En el planteamiento anterior interviene en el momento político, justo después de haber generado riqueza. Ahora se trata de plantear la justicia desde el primer momento, en el núcleo de la actividad económica, de la actividad política y de la conducta humana. La justicia social no es posterior o colateral a la creación de la riqueza, tiene que ser simultánea, estar en todo el proceso $\left(\mathrm{n}^{\circ} 37\right)$.

b. El mercado no produce la cohesión social que necesita la Economía para su funcionamiento. Sin formas internas de solidaridad y confianza recíproca, el mercado no podría cumplir su función económica. La clave de la crisis económica de hoy está en la falta de confianza, y esta no viene después del funcionamiento de la economía o la política, presupone ambos ámbitos de la actividad humana.

c. Hace falta que en el mercado tengan cabida «actividades económicas de sujetos que optan libremente por ejercer su 
gestión movidos por principios distintos al mero beneficio, sin renunciar por ello a producir valor económico. Muchos planteamientos provenientes de iniciativas religiosas y laicas demuestran que esto es posible» $\left(\mathrm{n}^{\circ} 37\right)$.

d. El contrato es una figura necesaria pero insuficiente para entender la gestión empresarial. El derecho y las normas jurídicas garantizan mínimos éticos en la gestión pero no generan la preocupación, motivación e ilusión que necesitan el equipo de personas que trabajan juntos en una organización. La economía globalizaba parece privilegiar la primera lógica mercantil (contrato), pero directa e indirectamente demuestra que necesita a las otras dos, la lógica de la política (cohesión social) y la lógica del don (caridad) (n $\left.n^{\circ} 37\right)$.

e. Además de la empresa privada y la empresa pública, hay otras formas de empresa, como organización productiva que persigue fines mutualistas y sociales. De la recíproca interacción de todas puede emerger una civilización de la economía. En este caso, caridad en la verdad significa «necesidad de dar forma y organizar iniciativas económicas que, sin renunciar al beneficio, quieren ir más allá de la lógica del intercambio de cosas equivalentes y del lucro como fin en sí mismo» $\left(n^{\circ} 38\right)$.

\section{Conclusión: una encíclica hermenéuticamente revolucionaria}

La encíclica es hermenéuticamente revolucionaria porque proporciona claves de interpretación novedosa. Hemos mostrado que la articulación conceptual de globalización, deliberación y donación rompe con los parámetros habituales de las ciencias sociales. El hecho de que el texto y las propuestas que realiza procedan de una matriz teológica no las invalida para enriquecer una ética social necesitada de renovación permanente.

Es difícil construir una ética social y económica sin lo que la encíclica describe como «sistema de referencia moral». Benedicto XVI no obliga ni exige la utilización del sistema de referencia moral que nace de la doctrina social de la iglesia, se atreve a ofrecerlo a la opinión pública para enriquecer la deliberación. Es probable que muchos filósofos o científicos sociales consideren innecesario trabajar con un marco de 
referencia moral, sin embargo puede ser un recurso imprescindible para clarificar las propias posiciones como investigadores y facilitar el cada día más urgente trabajo interdisciplinar.

Por último, la encíclica es hermenéuticamente revolucionaria porque normaliza el lugar de la caridad en la ética social. Desprovista de sus referencias sentimentales o emocionales, la caridad entra con la categoría de donación para repensar de nuevo una ética social de dimensiones globales. Con ello quizá no se produzca una reforma inmediata del sistema económico pero sí se proporcionan elementos para que los empresarios, los directivos, líderes de organizaciones y los responsables de instituciones revisen lo que entienden por «responsabilidad social». Una revisión que puede comenzar analizando lo que a continuación planteamos en el cuadro como «coordenadas para un nuevo management».

\begin{tabular}{|l|l|l|}
\hline & $\begin{array}{l}\text { Management } \\
\text { tradicional (enfoque } \\
\text { restringido) }\end{array}$ & $\begin{array}{l}\text { Nuevo Management } \\
\text { (enfoque ampliado) }\end{array}$ \\
\hline $\begin{array}{l}\text { Actividad } \\
\text { económica }\end{array}$ & $\begin{array}{l}\text { Actividad } \\
\text { complementaria de } \\
\text { otras }\end{array}$ & $\begin{array}{l}\text { Actividad intrínsecamente } \\
\text { humana }\end{array}$ \\
\hline Mercado & $\begin{array}{l}\text { Confianza ciega, } \\
\text { mercado competitivo }\end{array}$ & $\begin{array}{l}\text { Confianza crítica, economía } \\
\text { social de mercado }\end{array}$ \\
\hline $\begin{array}{l}\text { Empresa y } \\
\text { organizaciones }\end{array}$ & $\begin{array}{l}\text { Separación de sectores } \\
\text { profit/non profit) }\end{array}$ & $\begin{array}{l}\text { Pluralidad de formas } \\
\text { institucionales }\end{array}$ \\
\hline Management & $\begin{array}{l}\text { Responsabilidad social } \\
\text { funcional (condicio- } \\
\text { nada a obtención de } \\
\text { beneficio) }\end{array}$ & $\begin{array}{l}\text { Responsabilidad social } \\
\text { integrada (visión holista del } \\
\text { beneficio y la creación de } \\
\text { valor) }\end{array}$ \\
\hline $\begin{array}{l}\text { Democracia } \\
\text { económica }\end{array}$ & $\begin{array}{l}\text { Prioridad de la la } \\
\text { producción eficiente } \\
\text { para distribución justa }\end{array}$ & $\begin{array}{l}\text { Simultaneidad originaria de } \\
\text { justicia y solidaridad en } \\
\text { producción y distribución }\end{array}$ \\
\hline $\begin{array}{l}\text { Epistemología de } \\
\text { la Ciencia } \\
\text { económica }\end{array}$ & $\begin{array}{l}\text { Autonomía yeutrali- } \\
\text { dad. Indiferente a a } \\
\text { Ecología y Antropo- } \\
\text { logía }\end{array}$ & $\begin{array}{l}\text { Interdisciplinariedad. } \\
\text { Identificado con una responsa- } \\
\text { bilidad integral: económica, } \\
\text { social y ecológica }\end{array}$ \\
\hline $\begin{array}{l}\text { Figura del } \\
\text { «Manager» }\end{array}$ & $\begin{array}{l}\text { Indiferente a los } \\
\text { sistemas de referencia } \\
\text { moral }\end{array}$ & $\begin{array}{l}\text { Preocupado por un sistema de } \\
\text { referencia moral con síntesis } \\
\text { humanista }\end{array}$ \\
\hline
\end{tabular}


Sumario: Introducción; I. La desprivatización de la caridad en la ética social; 1. Un punto de partida revolucionario; 2. Usos y abusos de la ética; 3. Lógica de la equivalencia y lógica de la donación; II. Cambios en ética social: globalización, deliberación y donación; 1. Globalización: horizonte de responsabilidad social; 2. Deliberación: necesidad de un marco de referencia moral; 3. Donación: opción por una antropología integral; III. El lugar de la caridad en la ética empresarial; 1. Conducir personas con responsabilidad social; 2. Atender corresponsablemente los procesos para generar valor; 3. Dirigir organizaciones con razón cordial; Conclusión: una encíclica hermenéuticamente revolucionaria. 